\title{
Caracterização de sintomas visuais de deficiências de macronutrientes e boro em plantas de gengibre ornamental ${ }^{(1)}$
}

\author{
VIVIANE AMARAL TOLEDO COELHO(2); CLEBER LAZARO RODAS(2); \\ LÍVIA CRISTINA COELHO(2); JANICE GUEDES DE CARVALHO(2); \\ ELKA FABIANA APARECIDA ALMEIDA ${ }^{(3)}$; MARISLAINE ALVES DE FIGUEIREDO(2)
}

\begin{abstract}
RESUMO
O objetivo deste trabalho foi caracterizar os sintomas visuais de deficiência de macronutrientes e boro em plantas de gengibre ornamental em solução nutritiva. O experimento foi conduzido em casa de vegetação do DCS/UFLA, LavrasMG. O esquema estatístico utilizado foi o DIC com três repetições, contendo oito tratamentos, em solução nutritiva de Hoagland e Arnon (1950). Os tratamentos foram: solução nutritiva completa (controle) e soluções nutritivas com omissões individuais de $\mathrm{N}, \mathrm{P}, \mathrm{K}, \mathrm{Ca}, \mathrm{Mg}, \mathrm{S}$ e B. Após a germinação, as mudas foram transferidas para a solução nutritiva completa $10 \%$ da sua força iônica, permanecendo sob aeração constante. As plantas foram selecionadas quanto à uniformidade de tamanho da parte aérea e raízes. Posteriormente, foram transplantadas para vasos de plástico (8 litros) com solução nutritiva a 100\%. Os sintomas observados foram fotografados e descritos. Após a manifestação dos sintomas visuais de deficiência, as plantas foram colhidas. As plantas submetidas à omissão de $\mathrm{N}$ apresentaram clorose generalizada das folhas mais velhas, evoluindo para toda a planta, e porte reduzido. As omissões de $\mathrm{K}$ e Ca ocasionaram redução do crescimento da planta (parte área e raiz) quando comparado com o tratamento completo. As plantas sob omissão de $\mathrm{Mg}$ inicialmente apresentaram clorose internerval no ápice das folhas mais velhas e com o avanço dos sintomas as áreas cloróticas evoluíram para necroses marginais. As plantas cultivadas com omissão de S não apresentaram sintomas visuais de deficiência. Já as plantas com deficiência de B apresentaram folhas mais novas menores, mal-formadas e encarquilhadas, e algumas praticamente não apresentavam limbo foliar. As omissões dos nutrientes $\mathrm{N}, \mathrm{P}, \mathrm{K} \mathrm{Ca}$, e B Mg causam alterações morfológicas traduzidas em sintomas visuais de deficiência. A manifestação dos sintomas de deficiência ocorre primeiramente nos tratamentos com omissão de $\mathrm{N} \mathrm{e} \mathrm{Mg}$, sendo as deficiências de $\mathrm{N}, \mathrm{Ca}$ e $\mathrm{K}$ as que mais afetam a parte área. A omissão de macronutrientes e de boro afeta os índices biométricos e a produção de matéria seca de gengibre ornamental.
\end{abstract}

Palavras-chave: solução nutritiva, omissões de nutrientes, plantas ornamentais, Zingiber spectabile.

\section{ABSTRACT \\ Macronutrients and boron deficiency visual symptoms characterization in ornamental ginger}

The aim of this study was to describe the typical symptoms of macronutrients and boron deficiency in ornamental ginger plants grown in a nutritional solution based on Hoagland e Arnon's nutritional solution. The experiment was carried out in a greenhouse conditions at DCS / UFLA, Lavras-MG. The experiment was arranged in a completely randomized design with tree replications and eight treatments corresponding to the complete solution (control) and individual omissions of N, P, K, $\mathrm{Ca}, \mathrm{Mg}, \mathrm{S}$ and $\mathrm{B}$. N deficient plants showed yellowing of older leaves, progressing to the whole plant and small size. The omission of $\mathrm{K}$ and $\mathrm{Ca}$ caused plant growth reduction (root and shoot) when compared with the control treatment. The plants under omission of $\mathrm{Mg}$ initially showed interveinal paling at the apex of older leaves and with the advance of symptoms, chlorotic areas tranformed in marginal necrosis. The plants deficient in S did not show visual symptoms. B deficient plants showed smaller younger leaves, wrinkled, malformed and some plants had almost no leaves. The omissions of N, P, K, Ca, $\mathrm{Mg}$ and $\mathrm{B}$ in nutritional solution result in morphological changes, which reflect in characteristic symptoms of deficiency for each nutrient. The manifestation of deficiency symptoms first occurs in treatments with the omission of $\mathrm{N}$ and $\mathrm{Mg}$. $\mathrm{N}, \mathrm{Ca}$ and $\mathrm{K}$ are the nutrients that most affect shoot plant. The omission of macronutrients and boron affect the biometric indices and dry matter production of Zingiber spectabile.

Keywords: nutrient solution, nutrient omissions, ornamental plants, Zingiber spectabile.

\section{INTRODUÇÃO}

O agronegócio de flores e plantas ornamentais vem se expandindo no Brasil devido principalmente às condições climáticas que favorecem o cultivo de flores de clima temperado e tropical. Em função dessa diversidade climática, é possível produzir internamente flores, folhagens e outros derivados, todos os dias do ano a um custo competitivo (FRANÇA e MAIA, 2008).

Esse ramo se consolida como uma atividade econômica relevante, porém o principal aspecto deste segmento é o seu lado social. O agronegócio de flores e plantas ornamentais é uma atividade dominada por pequenos produtores rurais, contribuindo para uma melhor distribuição de

\footnotetext{
(1)Recebido em 27/01/2011 e aceito para publicação em 17/04/2012

${ }^{(2)}$ Laboratório de Nutrição Mineral de Plantas - Departamento de Ciência do Solo - Universidade Federal de Lavras, CxPostal: 3037, Lavras - MG, CEP: 37200-000, e-mail: vivianeatc@yahoo.com.br

${ }^{(3)}$ Núcleo Tecnológico EPAMIG Floricultura, Avenida Visconde do Rio Preto, S/N, Colônia do Bengo, CEP. 36.301-360, São João del Rei - MG
} 
renda. A capacidade de geração de ocupação e renda da floricultura é muito grande, emprega aproximadamente 120 mil pessoas, sendo $80 \%$ da mão de obra formada por mulheres, além de $18,7 \%$ de origem familiar. Entre as culturas agrícolas, a floricultura destaca-se por empregar, em média, de 10 a 15 funcionários por hectare, superando em dez vezes os demais cultivos (FRANÇA e MAIA, 2008).

De acordo JUNQUEIRA e PEETZ (2008), o mercado interno no ano de 2007 foi de US\$ 1,3 bilhões, e as exportações conquistaram sucessivos recordes ao longo da década, com valores de cerca de US\$ 35 milhões, correspondendo a $2,7 \%$ do valor total da produção, para países como Holanda, Estados Unidos, Japão, Espanha e França. Dados mais recentes obtidos no primeiro semestre de 2010 mostram que a floricultura brasileira exportou US\$14,287 milhões, o que representou aumento de $1,64 \%$ quando comparado ao mesmo período do ano de 2009 (JUNQUEIRA e PEETZ, 2010). O Brasil também se destacou frente aos países vizinhos mesmo diante da crise econômica que ocorreu durante o período citado (JUNQUEIRA e PEETZ, 2010).

As flores de plantas tropicais possuem características favoráveis ao comércio, como beleza, exotismo, várias cores e formas, resistência ao transporte e durabilidade póscolheita. A procura por estas plantas para ornamentação aumenta cada dia no mercado nacional, sendo antúrios, helicônias, alpínias, estrelícias, bastões-do-imperador e gengibres ornamentais as principais espécies cultivadas (LUZ et al., 2005).

O gengibre ornamental (Zingiber spectabile) pertence à família Zingiberaceae, sendo também conhecido como xampu, maracá ou sorvetão. É uma planta ornamental tropical, nativa da Malásia, herbácea, rizomatosa, robusta, perene, com hastes mais ou menos eretas, que podem atingir até $2,50 \mathrm{~m}$ de altura. Possui folhas alongadas, lanceoladas e aveludadas na parte inferior. Requer solos ricos em matéria orgânica e úmidos para um desenvolvimento satisfatório (LAMAS, 2004; TERAO et al., 2005). Apresenta inflorescências com brácteas amarelas até a coloração róseo-avermelhada. Essas inflorescências têm se mostrado muito resistentes ao manuseio, e sua durabilidade é bem grande, além da produtividade excepcional associada ao perfume levemente adocicado. A produtividade pode chegar a 100 flores/ano/touceira (LAMAS, 2004; LORENZI e MELO FILHO, 2001).

Para conseguir um melhor padrão de qualidade, é necessário um balanço adequado de nutrientes. Embora a literatura sobre espécies ornamentais seja ampla, a parte referente à nutrição e adubação dessas plantas ainda deixa grandes lacunas de informações quanto às exigências nutricionais e à identificação de problemas na produção decorrentes de estresses nutricionais, deficiências ou excessos.

Diante do exposto, o objetivo deste trabalho foi caracterizar os sintomas visuais de deficiência de macronutrientes e boro, bem como o crescimento e produção de matéria seca em plantas de gengibre ornamental, em solução nutritiva.

\section{MATERIAL E MÉTODOS}

O experimento foi conduzido durante de fevereiro de 2009 a fevereiro de 2010, em casa de vegetação do Departamento Ciência do Solo, na Universidade Federal de Lavras (Lavras, MG), cujas coordenadas geográficas são $21^{\circ} 14^{\prime} 30^{\prime}$ de latitude Sul e 4500'10" de longitude Oeste, altitude de $918 \mathrm{~m}$ (BRASIL, 1992).

As plantas de gengibre ornamental, utilizadas no experimento, foram propagadas via semente, germinadas em bandeja de poliestireno expandido com 72 células individualizadas contendo vermiculita. Trinta dias após a germinação, as mudas foram transferidas para a solução nutritiva completa de HOAGLAND e ARNON (1950), com $10 \%$ da sua força iônica (período de adaptação), sob aeração constante. $\mathrm{O}$ período de adaptação das plantas à solução nutritiva teve duração de 150 dias. As soluções foram trocadas quinzenalmente, e a sua força iônica aumentada gradativamente, a cada 15 dias, até atingir 100\%.

Após o período de adaptação, as plantas foram transplantadas para vasos com capacidade para 8 litros e aplicados os tratamentos por meio da técnica do elemento faltante. $\mathrm{O}$ delineamento experimental foi inteiramente casualizado com três repetições e oito tratamentos: Solução HOAGLAND e ARNON (1950) completa (controle), solução completa menos N (-N), solução completa menos $\mathrm{P}(-\mathrm{P})$, solução completa menos K (-K), solução completa menos $\mathrm{Ca}(-\mathrm{Ca})$, solução completa menos $\mathrm{Mg}(-\mathrm{Mg})$, solução completa menos $\mathrm{S}(-\mathrm{S})$ e solução completa menos boro (-B). Cada parcela foi constituída de uma planta por vaso.

Os vasos foram pintados em sua superfície externa com tinta alumínio, tendo sido colocada uma tampa de isopor, contendo pequeno orifício no centro, para a fixação da planta. As trocas de soluções foram feitas quinzenalmente.

$\mathrm{Na}$ preparação de todas as soluções estoque dos nutrientes, foram utilizados reagentes para análise (PA). As soluções nutritivas foram preparadas utilizando-se água deionizada e, durante o intervalo de renovação das soluções, o volume dos vasos foi completado, sempre que necessário, utilizando-se água deionizada.

As plantas foram monitoradas diariamente quanto ao aparecimento dos sintomas de deficiência nutricional, que foram descritos e fotografados. Após a manifestação dos sintomas de deficiência, procedeu-se à colheita das plantas, separando-as em folhas, hastes, rizoma e raízes.

Ao final do experimento, foram avaliadas as seguintes variáveis: altura da haste principal, número de hastes, diâmetro da haste principal e número de folhas da haste principal.

O material foi colhido, lavado em água destilada, acondicionado em saco de papel e colocado em estufa com circulação forçada de ar, a $65-70{ }^{\circ} \mathrm{C}$, até peso constante. Posteriormente, o material vegetal foi pesado em balança de precisão para a determinação do peso da matéria seca.

Os dados obtidos foram submetidos à análise de variância e as médias avaliadas pelo teste SCOTT e KNOTT a $5 \%$ de probabilidade. As análises estatísticas foram realizadas com o programa computacional Sisvar (FERREIRA, 2003). 


\section{RESULTADOS E DISCUSSÃO}

\section{Deficiência de Nitrogênio (N)}

As plantas cultivadas sob omissão de $\mathrm{N}$ começaram a apresentar sintomas de deficiência a partir de 30 dias da instalação do experimento. Os primeiros sintomas apresentados foram clorose generalizada nas folhas mais velhas (Figura 1). Com o avanço da deficiência, toda a planta se mostrou clorótica além de menor crescimento e redução no número de hastes e folhas. Nas folhas mais velhas, foi observada leve necrose na sua extremidade em plantas de bananeira ornamental, resultados similares foram observados por PINHO (2007) e, em plantas de mamoneira, por SEVERINO (2008).

De acordo MALAVOLTA (2006), a deficiência de N causa primeiramente clorose generalizada das folhas mais velhas pela sua proteólise, resultando no colapso dos cloroplastos, ocorrendo declínio dos teores de clorofila. Os sintomas ocorrem primeiramente nas partes mais velhas da planta, e os aminoácidos resultantes da proteólise são mobilizados para as partes mais novas, visto que o $\mathrm{N}$ é um nutriente de alta mobilidade no tecido vegetal. Com o agravamento da deficiência, toda a planta se torna clorótica pelo baixo teor de clorofila. Esses sintomas são típicos da carência desse nutriente (BERGMANN, 1987; MALAVOLTA, 2006).

SOUZA e FERNANDES (2006) explicam que a degradação da clorofila decorrente da deficiência de $\mathrm{N}$ não tem como objetivo mobilizar nutrientes, mas sim livrar a planta de compostos tóxicos de clorofila que são altamente reativos e liberados dos complexos proteína-pigmentos que compõem a membrana dos tilacoides dos cloroplastos.

O menor desenvolvimento em geral das plantas com carência de $\mathrm{N}$ é explicado pelo seu papel no metabolismo vegetal, uma vez que esse nutriente está presente em todas as proteínas e ácidos nucleicos da planta (MALAVOLTA e MORAES, 2007).

\section{Deficiência de Fósforo (P)}

Após 56 dias da instalação do experimento, as plantas com carência de $\mathrm{P}$ começaram a manifestar os sintomas de deficiência. Os primeiros sintomas verificados nas plantas sob deficiência desse nutriente ocorreram nas folhas mais velhas devido à alta mobilidade de $\mathrm{P}$ nos tecidos vegetais, (Figura 2), sendo essa mobilidade explicada por diversos autores (MARSCHNER, 1995, MENGEL e KIRKBY, 1987). Essas folhas apresentaram clorose, que evoluiu para necrose, que se estendia da extremidade até metade do limbo foliar. Segundo BERGMANN (1992), plantas sob deficiência de $\mathrm{P}$ podem apresentar manchas necróticas marrom-escuras nas folhas velhas, lesões necróticas nas margens das folhas e morte com queda de folhas mais velhas. Resultados semelhantes foram observados por FRAZÃO (2008), em plantas de bastão-do-imperador.

Não foram verificados sintomas característicos da deficiência de $\mathrm{P}$, como coloração arroxeada ou verdeescura como descrito para outras espécies. Nas raízes, verificou-se que estas manchas eram menos densas e com coloração mais escura. FRAZÃO (2008), estudando plantas de bastão-do-imperador, observou clorose das folhas mais velhas, também verificado por PINHO (2007) em bananeira ornamental.

De acordo TAIZ e ZEIGER (2004), assim como pode ocorrer na deficiência de $\mathrm{N}$, algumas espécies sob deficiência de $\mathrm{P}$ podem produzir antocianinas em excesso, conferindo às folhas coloração levemente arroxeada. Isso ocorre porque a deficiência de fósforo provoca a inibição da síntese de carboidratos, aumentando os teores de açúcares, o que estimula a síntese de antocianina (BERGMANN, 1992; MARSCHNER, 1995).

\section{Deficiência de Potássio (K)}

As plantas sob carência de $\mathrm{K}$ apresentaram sintomas de deficiência após 51 dias após estabelecidos os tratamentos. Inicialmente ocorreu redução no crescimento das plantas e, com o avançar do tempo, as folhas mais velhas apresentaram clorose com posterior necrose na sua extremidade, que se prolongava até aproximadamente um terço do limbo foliar (Figura 3). Também foi verificado que nessas folhas mais velhas existiam alguns pontos cloróticos que evoluíram para necrose. Sintomas semelhantes foram observados por PINHO (2007) em plantas de banana ornamental.

As raízes das plantas sob omissão de $\mathrm{K}$ eram menos desenvolvidas em comparação ao tratamento completo. Sintomas semelhantes foram observados por NAIFF (2007) em plantas de Alpinia purpurata.

$\mathrm{O} \mathrm{K}$ desempenha papel importante na regulação do potencial osmótico das células vegetais e ativação de aproximadamente 50 enzimas. Devido a esse fato, sua deficiência acarreta primeiramente redução do crescimento vegetal (FAQUIN, 2005; MALAVOLTA et al., 1997).

$\mathrm{O}$ primeiro sintoma característico da deficiência de K é a clorose marginal, que evolui para uma necrose, ocorrendo nas folhas mais velhas pela mobilidade desse elemento no tecido vegetal (MALAVOLTA et al, 1997). Esses sintomas ocorrem pelas mudanças químicas nas plantas deficientes em K, como aumento no teor de putrescina, no conteúdo de ácidos orgânicos e menor teor de açúcar de amido nos órgãos de reserva (MALAVOLTA, 2006).

\section{Deficiência de Cálcio (Ca)}

Os sintomas de carência de Ca se manifestaram 54 dias após a implantação do experimento e foram caracterizados por clorose seguida por necrose das folhas mais jovens (Figura 4). FRAZÃO (2008), estudando deficiências nutricionais em plantas de bastão-do-imperador, descreveu sintomas de deficiência semelhantes aos encontrados neste estudo.

Os vegetais utilizam $\mathrm{Ca}$ na síntese da parede celular, em particular na lamela média, que separa as células em divisão, além do requerido para funcionamento normal das membranas vegetais. Por esse fato, os sintomas de carência desse elemento ocorrem nas partes mais jovens, tanto na parte aérea como no sistema radicular (TAIZ e ZEIGER, 2004).

O sintoma típico da ausência de Ca é a necrose das 
regiões meristemáticas jovens, como ápices das raízes e folhas mais novas, provavelmente pela dissolução da parede celular. Para as folhas mais jovens, o primeiro sintoma é clorose nas suas extremidades e, nos estágios mais avançados, ocorre necrose (EPSTEIN e BLOOM 2004). Isso porque o Ca é fundamental para a permeabilidade das membranas e para a manutenção da integridade celular, sendo requerido para a divisão e expansão das células.

\section{Deficiência de Magnésio (Mg)}

De modo semelhante à deficiência de $\mathrm{N}$, as plantas sob omissão de $\mathrm{Mg}$ foram as primeiras a apresentar sintomas, o que aconteceu 37 dias após instalação do experimento. As plantas com deficiência desse nutriente inicialmente apresentaram sintoma típico, clorose internerval nas folhas mais velhas (Figura 5). Com o progredir do sintoma, as margens dessas folhas se tornaram também amareladas (chamado $\mathrm{V}$ invertido). Resultados semelhantes foram observados por PINHO (2007) em plantas de banana ornamental e por CASTRO (2007) em plantas de helicônia.

$\mathrm{O} \mathrm{Mg}$ tem função específica na ativação de enzimas envolvidas nos processos de respiração, fotossíntese e síntese de DNA e RNA (TAIZ e ZEIGER, 2004), contudo, seu papel mais bem conhecido é como componente da molécula de clorofila (MENGEL e KIRBY, 1987).

Os sintomas de carência de $\mathrm{Mg}$ são primeiramente visualizados nas folhas mais velhas pela mobilidade desse nutriente no tecido vegetal, caracterizados por clorose entre as nervuras (CARVALHO et al, 2001). Esse fato é justificado porque a clorofila nas nervuras permanece inalterada por períodos maiores que a clorofila do limbo foliar (entre as nervuras). Sob deficiência severa, toda a planta se torna clorótica (BERGMANN, 1992; TAIZ e ZEIGER, 2004).

\section{Deficiência de Enxofre (S)}

Durante o período experimental, não foram diagnosticados sintomas foliares de deficiência de $\mathrm{S}$. Esse resultado pode ser explicado pela absorção do $\mathrm{S}$ do ar pelas folhas, na forma de $\mathrm{SO}_{2}$, ainda que pouco eficiente (MALAVOLTA, 2006), o que pode ter atenuado as características sintomáticas da deficiência de $\mathrm{S}$ nesse trabalho. As plantas de gengibre ornamental também podem ter adquirido reservas de $\mathrm{S}$ durante a fase de adaptação suficiente para o desenvolvimento vegetativo.

\section{Deficiência de Boro (B)}

Os primeiros sintomas de deficiência de B foram observados 71 dias depois da instalação do experimento. Com o avançar do sintoma, as folhas lançadas pela planta eram menores, mal-formadas e encarquilhadas, e algumas praticamente não apresentavam limbo foliar (Figura 6). Também foi verificada superbrotação causada pela morte de meristema apical. Os sintomas de deficiência desse micronutriente ocorrem nos pontos de crescimento e partes mais jovens pela sua baixíssima mobilidade no tecido vegetal. Esses sintomas descritos anteriormente também foram descritos para outras espécies como bastãodo-imperador (FRAZÃO, 2008), bananeira ornamental (PINHO, 2007) e antúrio (FRAZÃO et al., 2009).

O B tem restrita mobilidade nas plantas, com os sintomas de deficiência aparecendo, primeiramente, em órgãos mais novos e meristemáticos, afetando assim o crescimento tanto da parte área como das raízes (CARVALHO et al., 2001).

Embora o papel que esse micronutriente desempenha no metabolismo vegetal não seja claro, várias funções lhe são atribuídas. Sua deficiência afeta o crescimento da planta provavelmente pelo seu envolvimento no metabolismo de AIA e de fenóis, como também pela necessidade de B para a síntese de bases nitrogenadas essenciais ao RNA, como a uracila, que pode causar até a morte dos pontos de crescimento e necrose em folhas novas (MALAVOLTA et al., 1997). As folhas e os ramos de plantas sob carência de B podem se tornar quebradiços pelo baixo conteúdo de água nesses órgãos, resultando em distúrbios na transpiração (MENGEL e KIRKBY, 1987).

\section{Variáveis de crescimento e produção de matéria seca}

Através das variáveis de crescimento avaliadas, observou-se que as omissões de nutrientes proporcionaram diferenças significativas nessas características.

Os resultados referentes à altura $(\mathrm{cm})$, diâmetro da haste principal $(\mathrm{cm})$, número de hastes e número total de folhas das plantas de gengibre ornamental cultivadas sob deficiência de macronutrientes e B são mostrados na Tabela 1.

Com exceção dos tratamentos com omissões de B e $\mathrm{S}$, todos os outros diferiram estaticamente do tratamento completo em relação à altura das plantas. As omissões de $\mathrm{N}, \mathrm{K}, \mathrm{P}, \mathrm{Ca}$ e $\mathrm{Mg}$ apresentaram reduções de 52,61; 52,$61 ; 45,18 ; 38,16$ e $34,28 \%$, respectivamente, quando comparados ao tratamento completo.

GONÇALVES et al. (2006), estudando deficiência de macronutrientes em umbuzeiro, constataram que, em relação à altura das plantas, os tratamentos que sofreram maiores reduções foram as omissões de $\mathrm{Ca}, \mathrm{N}$ e $\mathrm{Mg}$. Já PRADO e VIDAL (2008), estudando deficiências nutricionais em milheto, verificaram que, com exceção da omissão de $\mathrm{S}$, todas as plantas dos outros tratamentos foram negativamente afetadas pela deficiência de macronutrientes, tendo sido os menores valores encontrados nas omissões de $\mathrm{N}$ e Ca. Esses dados confirmam aqueles encontrados neste estudo.

As plantas cultivadas sob deficiências de N, P, K, $\mathrm{Ca}$ e $\mathrm{Mg}$ não diferiram estatisticamente entre si, porém, apresentaram diminuição no diâmetro do caule, quando comparadas à testemunha.

Em estudo conduzido por PRADO e LEAL (2006), em que plantas de girassol da variedade Catissol-01 foram submetidas a deficiências nutricionais, foi observado que as plantas sob omissões de N, P, K e Ca tiveram sua altura e diâmetro afetados.

$\mathrm{Na}$ avaliação do número de hastes de plantas de gengibre ornamental, observou-se que todas as omissões nutricionais estudadas resultaram na diminuição dessa característica em relação ao tratamento completo, sendo que as mais prejudiciais foram as deficiências de $\mathrm{N}, \mathrm{P}, \mathrm{K}$ e $\mathrm{Mg}$ com 
redução de 89,$76 ; 81,10 ; 70,23$ e $62,12 \%$, respectivamente, mas não apresentaram diferença estatística significativa entre si.

Quanto ao número de folhas, as mais afetadas foram as plantas dos tratamentos $\mathrm{N},-\mathrm{P},-\mathrm{K}$ e $-\mathrm{S}$ com reduções de 50,$00 ; 33,91 ; 33,91$ e $23,74 \%$, respectivamente, quando comparadas às plantas do tratamento completo.

YEH etal.(2000), em estudo de omissão de nutrientes em plantas de Spathiphyllum, verificaram que os tratamentos que mais afetaram o número de folhas corresponderam às plantas com omissões de N, P e Ca.

Os resultados referentes à matéria seca de folhas (MSFO), matéria seca de hastes (MSHA), matéria seca de rizoma (MSRZ) e matéria seca de raiz (MSRA) das plantas de gengibre ornamental sob deficiência de macronutrientes e B apresentaram diferenças significativas e são mostrados na Tabela 2.

Plantas cultivadas em solução nutritiva com omissão de S apresentaram valores superiores para MSFO e MSHA em relação às plantas cultivadas em solução completa. Já as plantas com ausência de $\mathrm{N}, \mathrm{Ca}, \mathrm{K}, \mathrm{P}$ e $\mathrm{Mg}$ tiveram a MSFO afetada, com reduções, em relação ao tratamento completo, de 88,$58 ; 88,58 ; 82,17 ; 81,50$; e $61,19 \%$, respectivamente. A MSHA para as plantas dos mesmos tratamentos citados anteriormente também foi afetada. Houve reduções de 95,$36 ; 94,92 ; 94,52 ; 91,88$ e $85,61 \%$ para os tratamentos -N, -P, -K, -Ca e-Mg, respectivamente, quando comparados às plantas às quais foram fornecidos todos os nutrientes.

Como observado para MSFO e MSHA, as plantas com carência de $\mathrm{S}$ apresentaram valores superiores estatisticamente diferentes de MSRZ em comparação com as plantas do tratamento completo. As menores produções de matéria seca dessa parte da planta foram observadas nas plantas com deficiência de K, N, P, Ca e Mg.

Houve redução na produção de MSRA de plantas cultivadas sob omissão de $\mathrm{Ca}, \mathrm{K}, \mathrm{N}, \mathrm{P}$ e Mg com valores, respectivamente, 84,$60 ; 83,60 ; 67,20 ; 66,80$ e $35,00 \%$ menores quando comparadas às plantas do tratamento completo.

Em estudo conduzido por UTUMI et al. (1999), foi verificado que plantas de estévia submetidas à deficiência de $\mathrm{S}$ obtiveram produção de matéria seca para as diferentes partes da planta semelhante ao tratamento completo. Em particular, a matéria seca da raiz apresentou valores quase duas vezes maiores que as plantas bem nutridas.

Ainda em relação às plantas de estévia, os mesmos autores verificaram que a matéria seca da parte área das plantas sob omissões de $\mathrm{N}, \mathrm{K}, \mathrm{Mg}$ e $\mathrm{P}$ foi a que sofreu menor redução, resultados que confirmam os observados no atual trabalho.

VELOSO e MURAOKA (1993), trabalhando com carência nutricional em pimenta-do-reino, observaram que as omissões de $\mathrm{N}$, Ca e $\mathrm{K}$ foram as que mais afetaram a produção de matéria seca total dessas plantas, diferindo do que ocorreu para os outros macronutrientes $(\mathrm{S}, \mathrm{Mg}$ e $\mathrm{P}$ ), que foram semelhantes estatisticamente ao tratamento completo.

Já BARROSO et al. (2005) verificaram que a matéria seca radicular de plantas de teca (Tectona grandis) não foi afetada pela deficiência de macronutrientes.

O menor desenvolvimento, em geral, das plantas com carência de $\mathrm{N}$ é explicado pelo papel desse nutriente no metabolismo vegetal, uma vez que está presente em todas as proteínas e ácidos nucleicos da planta (MALAVOLTA e MORAES, 2007).

O crescimento reduzido é um dos sintomas de carência de P por ser constituinte de compostos importantes do tecido vegetal, além de essencial nos processos de transferência de energia (MALAVOLTA et al, 1997).

O K desempenha papel importante na regulação do potencial osmótico das células vegetais e ativação de aproximadamente 50 enzimas. Devido a esse fato, sua deficiência acarreta, primeiramente, redução do crescimento vegetal (FAQUIN, 2005, MALAVOLTA et al., 1997).

A deficiência de $\mathrm{Ca}$ afeta o crescimento e o desenvolvimento das plantas pela paralisação da divisão celular, e com isso, a paralisação do crescimento. Esse crescimento reduzido ocorre tanto na parte aérea quanto nas raízes (EPSTEIN e BLOOM, 2004).

Entre as principais funções do $\mathrm{Mg}$, pode-se citar como elemento central da molécula de clorofila, além de ativador de diversas enzimas. Em particular, o Mg é co-fator da maioria das enzimas fosforilativas, formando uma ponte entre o pirofosfato do ADP ou ATP e a enzima (MALAVOLTA, 2006). Por isso, sua deficiência pode acarretar menor desenvolvimento dos vegetais.

\section{CONCLUSÕES}

As omissões dos nutrientes N, P, K Ca, Mg e B causam alterações morfológicas traduzidas em sintomas visuais de deficiência.

A manifestação dos sintomas de deficiência ocorre primeiramente nos tratamentos com omissão de $\mathrm{N}$ e $\mathrm{Mg}$ e os que mais afetam a parte área são as deficiências de $\mathrm{N}$, $\mathrm{Ca}$ e K.

A omissão de macronutrientes e de boro afeta os índices biométricos e a produção de matéria seca em gengibre ornamental.

As omissões de nutrientes que mais afetam a parte área das plantas de gengibre ornamental são as N, Ca e K.

O crescimento do sistema radicular de plantas de gengibre ornamental é mais afetado pela deficiência de K, $\mathrm{Ca}$ e $\mathrm{Mg}$.

\section{REFERÊNCIAS}

BARROSO, D. G.; FIGUEIREDO, F. A. M. M. A.; PEREIRA, R.C.; MENDONÇA, A.V. R.; SILVA, L. C. Diagnóstico de deficiências de macronutrientes em mudas de teca. Revista Árvore. Viçosa, v. 29, n. 5, p.671-679, 2005.

BERGMANN, W.Nutritional disorders of plants. New York: Gustav Fischer, 1992. 741p.

BRASIL. Ministério da Agricultura. Escritório de Meteorologia. Normas climatológicas: 1961-1990. Brasília: SNI/INME, 1992. 84 p.

CARVALHO, G. C.; LOPES, A. S.; BRASIL, E; REIS 
JUNIOR, R. A. Diagnose da fertilidade do solo e do estado nutricional das plantas. Lavras: UFLA/FAEPE, 2001, 95p.

CASTRO, A. C. R. Deficiência de macronutrientes em helicônia 'golden torch'. Universidade Federal Rural de Pernambuco, Recife-PE. 2007. 102p. Tese (Doutorado em Botânica).

EPSTEIN, E.; BLOOM, A. Mineral nutrition of plants. Sunderland: Sinauear Associates, 2004. 403p.

FAQUIN, V. Nutrição de plantas. Lavras: UFLA/FAEPE, 2005.183p.

FERREIRA, D.F. SISVAR software: versão 4.6. Lavras: DEX/UFLA, 2003. Software.

FRANÇA, C .A. M.; MAIA, M. B .R. Panorama do agronegócio de flores e plantas ornamentais no Brasil. Porto Velho: UNIR, 2008. 10p. Disponível em: http:// www.sober.org.br/palestra/9/761.p.... Acesso em 22 ago. 2010 .

FRAZÃO, J. E. M. Diagnose da deficiência nutricional e crescimento do Bastão-do-Imperador Etlingera elatior (Jack) R. M. Smith com o uso da técnica do elemento faltante em solução nutritiva. Lavras-MG: Universidade Federal de Lavras, 2008, 67p. Tese (Doutorado em Ciência do Solo).

FRAZÃO, J. E. M.; PINHO, P. J.; CARVALHO, G. C.; ALMEIDA, E. F. A. Caracterização da deficiência nutricional simples e conjunta de boro e zinco em plantas de antúrio (Anthurium andraeanum). Belo Horizonte: EPAMIG, 2009. Circular Técnica, 69.

FURLANI, A.M.C.; CASTRO, C.E.F. Plantas ornamentais e flores. In: FERREIRA, M.E.; CRUZ, M.C.P.; RAIJ, B.van. e ABREU, C.A., eds. Micronutrientes e elementos tóxicos na agricultura. Jaboticabal: CNPq/FAPESP/ POTAFÓS, 2001. p.533-552.

GONÇALVES, F. C.; NEVES, O. S. C. GUEDES, G. C. Deficiência nutricional em mudas de umbuzeiro decorrente da omissão de macronutrientes. Pesquisa Agropecuária Brasileira. Brasília, v.41, n.6, p.1053-1057, jun, 2006.

JUNQUEIRA, A. H; PEETZ, M. S. Mercado interno para os produtos da floricultura brasileira: características, tendências e importância socioeconômica recente. Revista Brasileira de Horticultura Ornamental. Campinas, v.14, n.1, p.37-52, 2008.

JUNQUEIRA, A. H. e PEETZ, M. S. Análise conjuntural do comércio exterior da floricultura brasileira. São Paulo, 2010. Disponível em: < http://www.florestropicais.net/ index.php?option $=$ com_content $\&$ view $=$ article $\& i d=2274$ : analise-conjuntural-do-comercio-exterior-da-floriculturabrasileira $\&$ catid $=8$ :aritos-e-pesquisas $\&$ Itemid $=12$. Acesso em 13 jan. 2010.
HOAGLAND, D.R.; ARNON, D.L. The water culture methods for growing plants whitout soil. California Agriculture Experiment Station, Berkeley, 1950. (Bulletin,v. 347), 1-32p.

LAMAS, A.M. Flores: Produção, Pós-colheita e mercado. Fortaleza-CE. 2004.109p. Disponível em: http://www.unitins.br/ates/arquivos/Agricultura/ P lantas $\% 20$ Ornamenta is / F 1 or es $\% 20-\% 20$ Produ\%C3\%A7\%C3\%A30\%20e\%20Mercado.pdf. Acesso em 30 ago. 2010.

LORENZI, H.; MELO FILHO, L. E. As plantas tropicais de R. Burble Marx. São Paulo: Instituto Plantarum de Estudos da Flora, 2001. 488p.

LUZ, P.B.; ALMEIDA, E.F.A.; PAIVA, P.D.O.; RIBEIRO, T.R. Cultivo de flores tropicais. In : Informe agropecuário. Belo Horizonte, 2005, v. 26, n.227, p.62-72.

MALAVOLTA, E. Manual de nutrição mineral de plantas. São Paulo: Editora Agronômica Ceres, 2006. $638 \mathrm{p}$.

MALAVOLTA, E.; MORAES, M.F. Fundamentos do nitrogênio e do enxofre na nutrição mineral das plantas. In: YAMADA, T.; ABDALLA S. E. S.; VITTI, G. C. Nitrogênio e Enxofre na Agricultura Brasileira. Piracicaba-SP: International Plant Nutrition Institute, 2007. p.189-249.

MALAVOLTA, E.; VITTI, G.C.; OLIVEIRA, S.A. Avaliação do estado nutricional das plantas: princípios e aplicações. 2.ed. Piracicaba: POTAFOS, 1997. 319p.

MARSCHNER, H. Mineral nutrition of higher plants. NY: Academic Press, 1995. 889p.

MENGEL, K.; KIRKBY, E.A. Principles of plant nutrition. 4.ed. Bern: International Potash Institute, 1987. $687 \mathrm{p}$.

NAIFF, A. P. M. Crescimento, Composição Mineral e Sintomas Visuais de Deficiências de Macronutrientes em Plantas de Alpinia purpurata cv. Jungle King. 2007. 77p. Tese de Mestrado. Universidade Federal Rural da Amazônia, Belém-PA.

PINHO, P. J. de. Deficiências nutricionais em bananeira ornamental (Musa velutina h. wendl. \& drude): Alterações químicas e morfológicas e caracterização de sintomas visuais. Lavras-MG. Universidade Federal de Lavras, 2007. 147p. Tese (Doutorado em Ciência do Solo).

PRADO, R.; LEAL, R. M. Desordens nutricionais por deficiência em girassol var. Catissol-01. Pesquisa Agropecuária Tropical. Goiânia, v.36, n.3, p.187-193, 2006.

PRADO, R. M.; VIDAL, A. A. Efeitos da omissão de macronutrientes em solução nutritiva sobre o crescimento e a nutrição do milheto. Pesquisa Agropecuária Tropical. 
v.38, p.208-214,2008.

SEVERINO, L. S.; SANTOS, F.D.S.; FERREIRA, G.B.; MORAES, C. R. A.; SAMPAIO, L .R.; FREIRE, M. A. O.; ALMEIDA, D. M.; SOFIATTI, V.; BELTRÃO, N. E. M. Descrição dos sintomas de deficiência nutricional na mamoneira. 1. Nitrogênio, Fósforo, Enxofre e Magnésio. In: CONGRESSO BRASILEIRO DE MAMONA, 3, Anais, Salvador, BA. Energia e Ricinoquímica. Campina Grande, PB: Embrapa Algodão, 2008.

SOUZA, S.R.; FERNANDES, M.S . Nitrogênio. In: FERNANDES, M.S. Nutrição mineral de plantas. Viçosa, MG: SBCS, 2006. p. 215-254.

TAIZ, L.; ZEIGER, E. Fisiologia vegetal. 3.ed. Porto alegre: Artmed, 2004. 719p.

TERAO, D.; CARVALHO, A.C.P.P.; BARROSO,
T.C.S. Flores tropicais. Brasília: Embrapa informação tecnológica, 2005. 225p.

UTUMI, M. M.; MONNERAT, P.H.; PEREIRA, P. R.G.; FONTES, P. C. R.; GODINHO, V. P. C. Deficiência de macronutrientes em estévia: Sintomas visuais e efeitos no crescimento, composição química e produção de esteviosídeo. Pesquisa Agropecuária Brasileira, Brasília, v.34, n.6, p.1039-1043, jun. 1999.

VEloso, C. A. C.; MURAOKA, T. Diagnóstico de sintomas de deficiência de macronutrientes em pimenteira do reino (Piper nigrum, L.). Scientia Agricola, Piracicaba, v.50, n.2, p. 232-236, 1993.

YEH, M. D.; LIN, L.; WRIGHT, C. J. Effects of mineral nutrient deficiencies on leaf development, visual symptoms and shoot root ratio of Spathiphyllum. Scientia Horticulturae, v.86, p.223-233, 2000.

Tabela 1. Altura (ALT), diâmetro da haste principal (DIAM), número de hastes (NH) e número de folhas (NF) de gengibre ornamental sob omissão de macronutrientes e boro, na colheita, UFLA, Lavras, MG, 2011

\begin{tabular}{ccccc}
\hline Tratamento & ALT $(\mathbf{c m})$ & DIAM $(\mathbf{c m})$ & NH & NF \\
\hline Completo & $83,00 \mathrm{a}$ & $0,97 \mathrm{~b}$ & $12,33 \mathrm{a}$ & $20,00 \mathrm{a}$ \\
$-\mathrm{N}$ & $39,33 \mathrm{~b}$ & $0,57 \mathrm{c}$ & $2,33 \mathrm{~d}$ & $10,00 \mathrm{c}$ \\
$-\mathrm{P}$ & $45,50 \mathrm{~b}$ & $0,40 \mathrm{c}$ & $3,33 \mathrm{~d}$ & $13,00 \mathrm{~b}$ \\
$-\mathrm{K}$ & $39,33 \mathrm{~b}$ & $0,47 \mathrm{c}$ & $3,67 \mathrm{~d}$ & $13,00 \mathrm{~b}$ \\
$-\mathrm{Ca}$ & $51,33 \mathrm{~b}$ & $0,53 \mathrm{c}$ & $9,33 \mathrm{~b}$ & $16,00 \mathrm{~b}$ \\
$-\mathrm{Mg}$ & $54,55 \mathrm{~b}$ & $0,43 \mathrm{c}$ & $4,67 \mathrm{~d}$ & $18,00 \mathrm{a}$ \\
$-\mathrm{S}$ & $69,00 \mathrm{a}$ & $1,20 \mathrm{a}$ & $7,00 \mathrm{c}$ & $15,00 \mathrm{~b}$ \\
$-\mathrm{B}$ & $73,73 \mathrm{a}$ & $1,00 \mathrm{~b}$ & $6,00 \mathrm{c}$ & $20,00 \mathrm{a}$ \\
\hline $\mathrm{CV}(\%)$ & 15,37 & 17,07 & 19,11 & 11,31 \\
\hline
\end{tabular}

Médias seguidas de mesma letra na coluna não diferem entre si, pelo teste Scott \& Knott a $5 \%$ de probabilidade.

Tabela 2. Produção de matéria seca de folha (MSFO), haste (MSHA), rizoma (MSR) e raiz (MSRA) de gengibre ornamental sob omissão de macronutrientes e boro, na colheita, UFLA, Lavras, MG, 2011

\begin{tabular}{ccccc}
\hline Tratamento & MSFO $(\mathbf{g})$ & MSHA $(\mathbf{g})$ & MSRZ $(\mathbf{g})$ & MSRA (g) \\
\hline Completo & $12,96 \mathrm{~b}$ & $20,08 \mathrm{~b}$ & $5,05 \mathrm{~b}$ & $5,00 \mathrm{a}$ \\
$-\mathrm{N}$ & $1,48 \mathrm{c}$ & $0,93 \mathrm{c}$ & $0,71 \mathrm{c}$ & $1,64 \mathrm{c}$ \\
$-\mathrm{P}$ & $2,33 \mathrm{c}$ & $1,02 \mathrm{c}$ & $0,75 \mathrm{c}$ & $1,66 \mathrm{c}$ \\
$-\mathrm{K}$ & $2,31 \mathrm{c}$ & $1,10 \mathrm{c}$ & $0,55 \mathrm{c}$ & $0,82 \mathrm{c}$ \\
$-\mathrm{Ca}$ & $1,48 \mathrm{c}$ & $1,63 \mathrm{c}$ & $1,38 \mathrm{c}$ & $0,77 \mathrm{c}$ \\
$-\mathrm{Mg}$ & $5,03 \mathrm{c}$ & $2,89 \mathrm{c}$ & $1,58 \mathrm{c}$ & $1,28 \mathrm{c}$ \\
$-\mathrm{S}$ & $25,93 \mathrm{a}$ & $28,34 \mathrm{a}$ & $8,76 \mathrm{a}$ & $3,35 \mathrm{~b}$ \\
$-\mathrm{B}$ & $10,06 \mathrm{~b}$ & $17,53 \mathrm{~b}$ & $9,49 \mathrm{a}$ & $5,55 \mathrm{a}$ \\
\hline $\mathrm{CV}(\%)$ & 27,65 & 32,60 & 25,65 & 26,14 \\
\hline
\end{tabular}

Médias seguidas de mesma letra na coluna não diferem entre si, pelo teste Scott \& Knott a 5\% de probabilidade. 


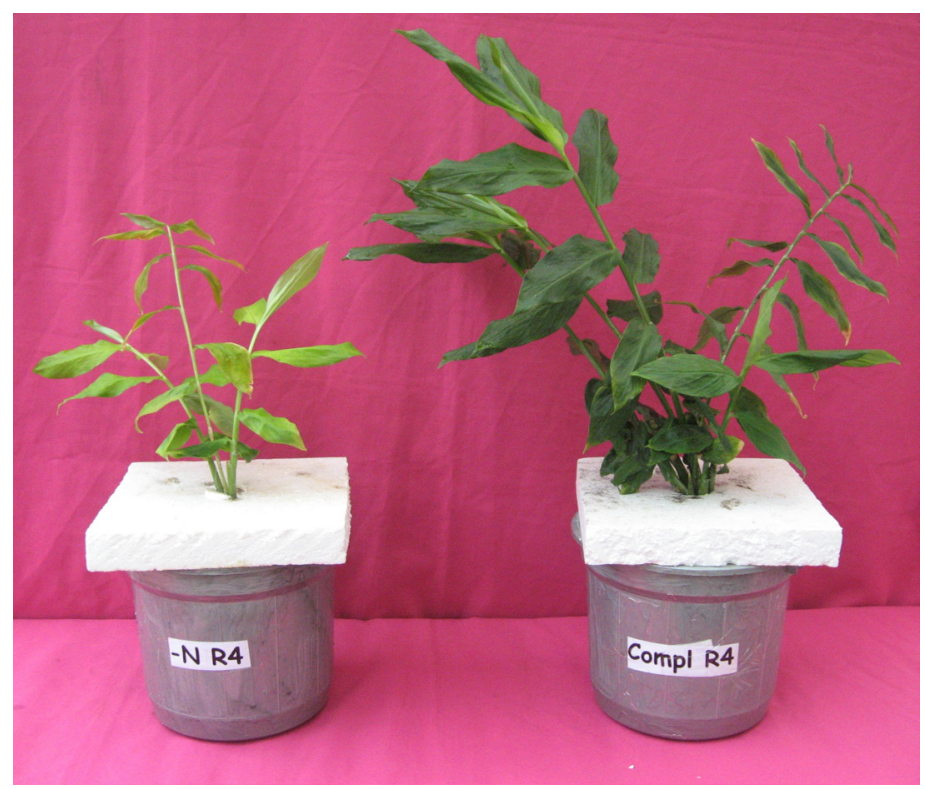

Figura 1. Sintomas visuais de deficiência de nitrogênio em gengibre ornamental: aspecto geral da parte aérea da planta sob deficiência (esquerda) comparada com planta do tratamento completo (direita). UFLA, Lavras, MG, 2011.

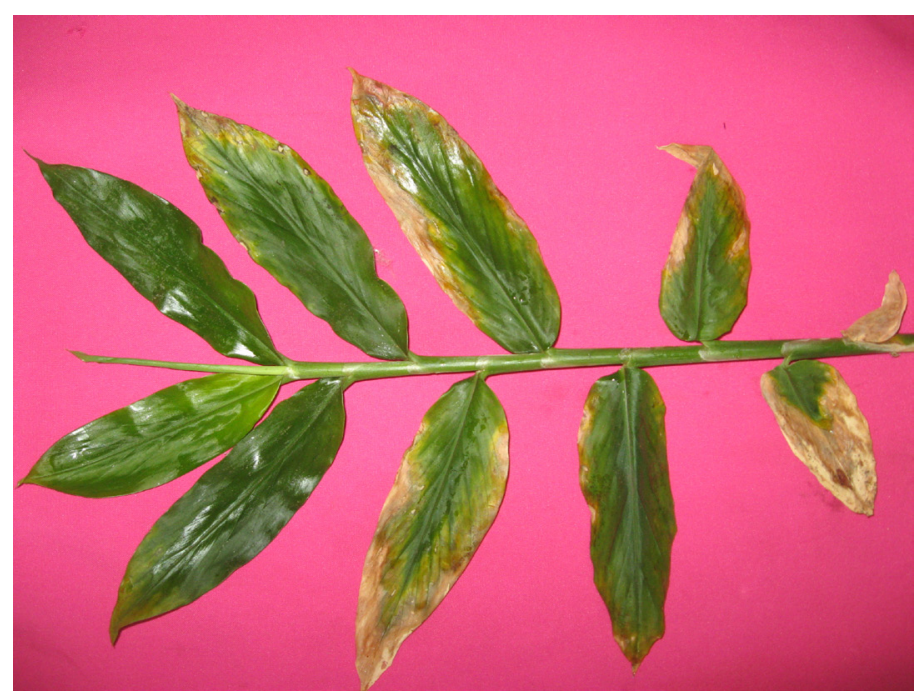

Figura 2. Sintomas visuais de deficiência de fósforo em gengibre ornamental: detalhe da haste sintomática. UFLA, Lavras, MG, 2011.

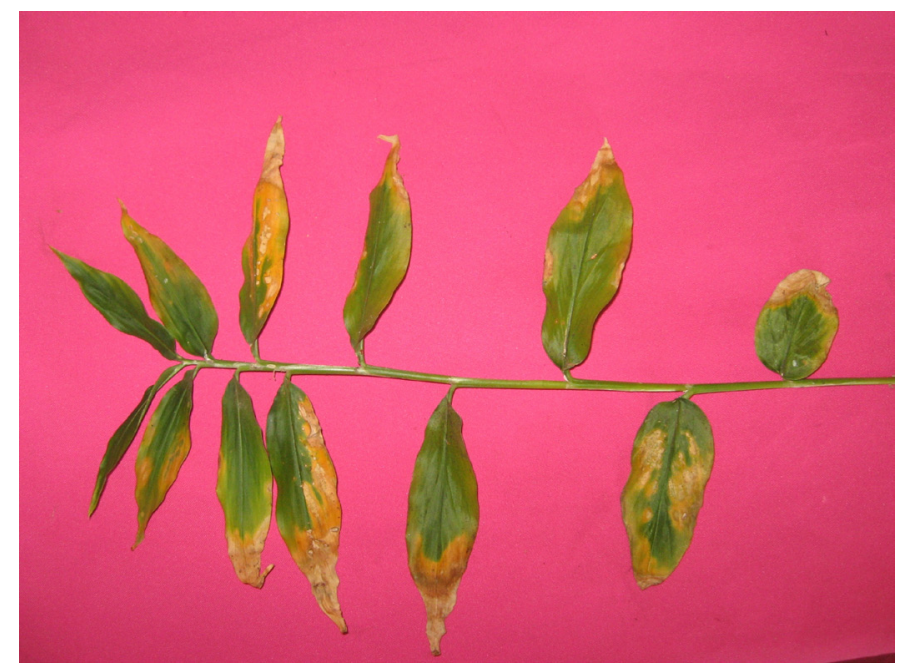

Figura 3. Sintomas visuais de deficiência de potássio em gengibre ornamental: detalhe da haste sintomática. UFLA, Lavras, MG, 2011. 


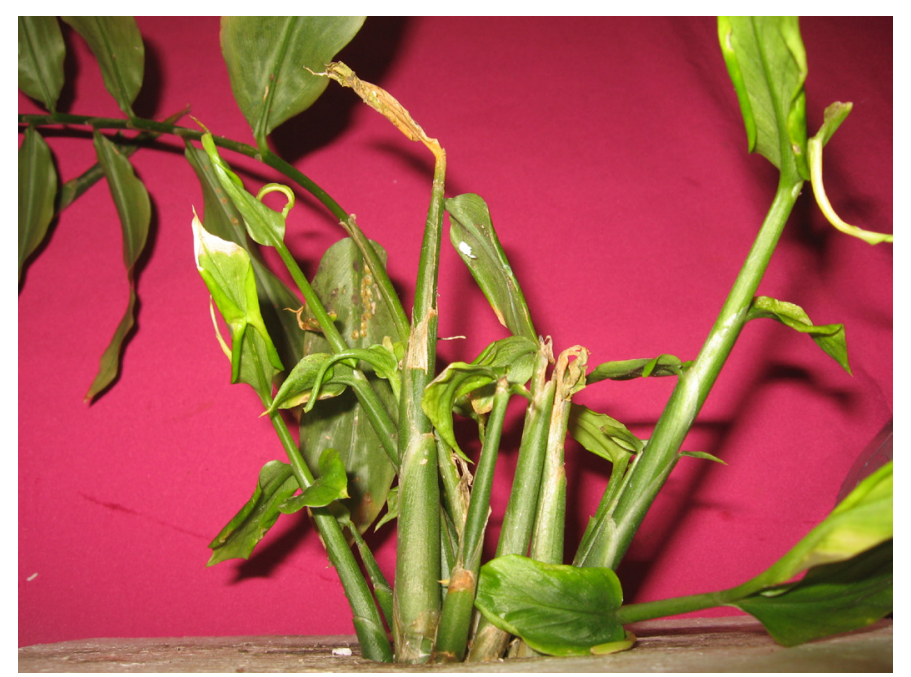

Figura 4. Sintomas visuais de deficiência de cálcio em gengibre ornamental: aspecto geral da parte aérea da planta sob deficiência. UFLA, Lavras, MG, 2011.

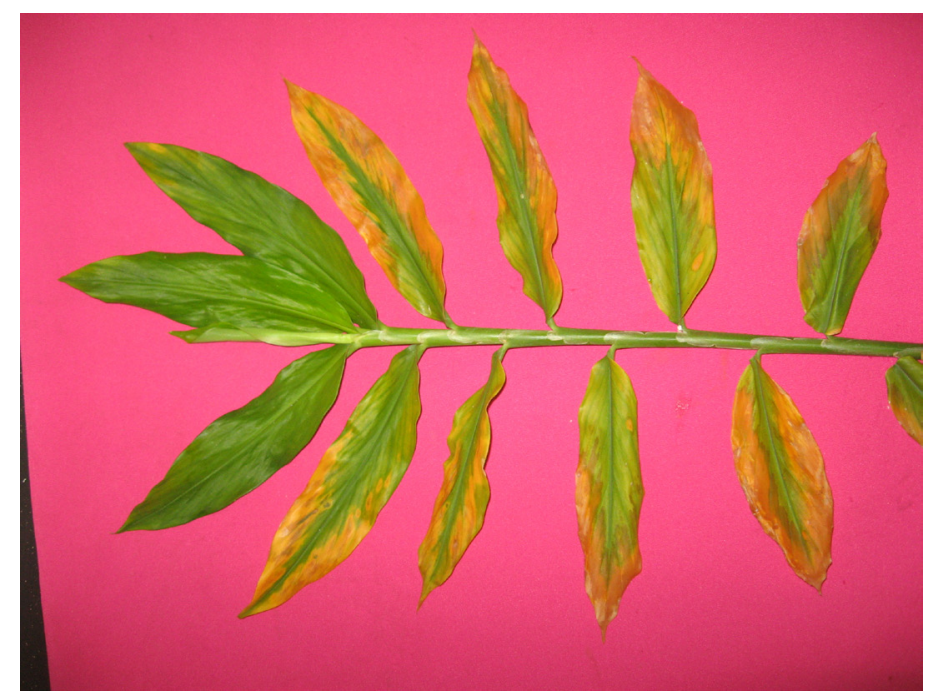

Figura 5. Sintomas visuais de deficiência de magnésio em gengibre ornamental: detalhe da haste sintomática. UFLA, Lavras, MG, 2011.

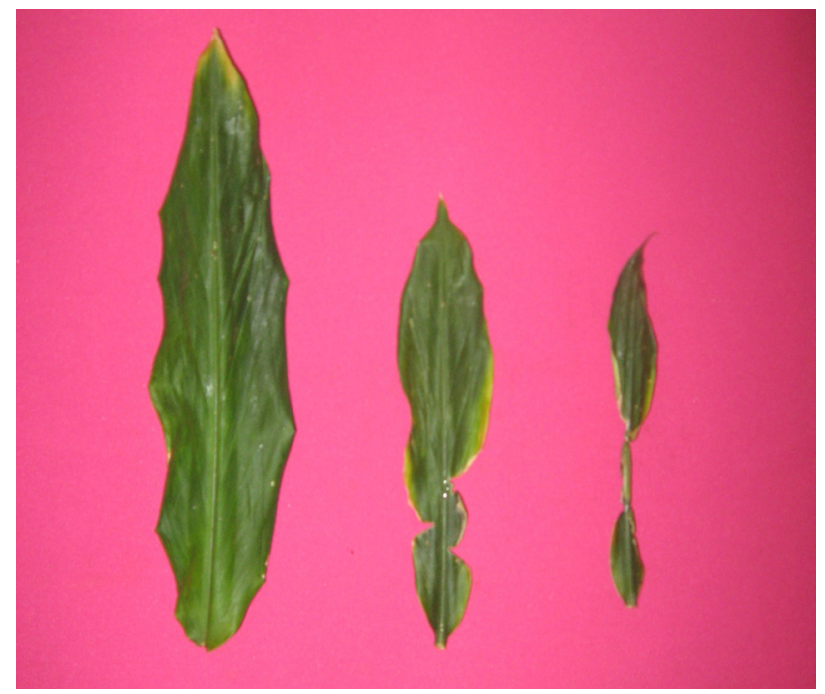

Figura 6. Sintomas visuais de deficiência de boro em gengibre ornamental: folha da planta sob deficiência (direita) comparada com a folha da planta do tratamento completo (esquerda). UFLA, Lavras, MG, 2011. 